\title{
reviews
}

Fish Communities in Tropical Freshwaters: Their Distribution, Ecology and Evolution. By R. H. LoweMcConnell. Pp. xvii +337 . (Longman: London and New York, 1975.) £10.

To those accustomed to the restricted fish fauna of British freshwaters, the diversity in tropical freshwaters is bewildering. More than 8,000 of the 20,000 modern fish species live in tropical rivers and lakes; these include many suborders not represented in higher latitudes, for example, the electric fishes of the unrelated Gymnotoidei and Mormyroidei. The need to refer to many species which will be unfamiliar to most readers poses a problem to the author, who tackles it by providing a general chapter about the fish faunas of Africa, South America and South-east Asia, including five pages of excellent drawings of representative genera, by listing all the families in an Appendix and by giving a separate index of fish names, including synonyms.

Five chapters compare fish communities in the four main types of tropical freshwaters: equatorial forest rivers; seasonal rivers; natural lakes; and manmade lakes. All the lakes are African but Dr Lowe-McConnell is able to compare rivers in the three continents. For each locality, she outlines the topography and geological history, and then describes climate and resulting changes in water conditions. This treatment brings out clearly the similarities between physical and chemical conditions in rivers of the three continents and helps to explain the remarkable convergences in the adaptations of the fishes and the general structure of the communities in these waters. In contrast to temperate waters, there is usually a diurnal and a nocturnal fauna which never meet. The regular flooding of large rivers is associated with the habit of feeding and breeding in the shallow productive flooded areas and then facing the problem of retreating to the restricted river channels when the floods subside.

In three other chapters, Dr LoweMcConnell makes a valuable contribution to current discussions about the origin and maintenance of diversity in tropical ecosystems by considering topics such as trophic relationships, breeding behaviour and speciation, especially in the African lakes. Her own wide experience in the tropics makes her comments vivid and penetrating.
This book should appeal to a variety of readers: it presents a comparative view of complex fish communities for all those interested in ecology and evolution; it provides a good basis for anyone starting detailed work on tropical fishes, either from an academic or from a practical point of view. The 20-page bibliography will be especially useful to fishery workers since it in-

\section{Tide turns for fisheries research}

cludes many papers which are relatively unknown because they are difficult to obtain. The only major complaint to make is the price-at $£ 10$, few students are likely to buy their own copies but it is a 'must' for teaching libraries as well as for many research workers. Margaret Varley

Fisheries Resources of the Sea and their Management. (Science and Engineering Policy Series.) By David Cushing. Pp. 87. (London: Oxford University, 1975.) $£ 3.50$.

THIS book is a brief but useful review of the world's fisheries to inform the uninformed. The first chapter deals with the recent history and development of the fisheries and fishing gear. The world catch of fish amounts to 65-70 million tons, the predominant species being the anchovies, sardines and herrings, followed by the cod-like fishes, together amounting to 25 million tons.

Japan and the USSR have become the biggest fishing nations but fisheries research is practised in most maritime countries, its foundation being hased mainly on work in the N.W. European countries. Dr Cushing gives a potted survey of age, growth, fecundity and migrations of fish, and the delimiting of stocks, with a longer chapter on fish population dynamics. Following the earlier regulation of fisheries by mesh sizes of nets, minimum sizes of fish for landing or by close seasons, there has been a trend towards allocating quotas to countries. In spite of research and control, overfishing is still prevalent. Nevertheless it is considered that up to 100 million tons could be taken annually, mainly by the exploitation of new stocks.

Dr Cushing surveys the history and practice of fisheries management and the various international councils and commissions. The international structure of management is extremely complex and these chapters are especially useful in giving a brief account of the efforts being made to control fisheries in a rational manner. Alas, national interests, fishermen's lobbies and disagreements between governments and scientists have meant that attempts at conservation have often ended in failure.

\section{J. H. S. Blaxter}

Principles of Fishery Science. By W. H. Everhart, A. W. Eipper and W. D. Youngs. Pp. 288. (Comstock: Ithaca, New York and London, September 1975.) $£ 6.85$.

Principles of Fishery Science is an updated abridged version of Fishery Science: Its Methods and Applications by Rounsefell and Everhart, first published in 1953 and aimed at graduate and upper division undergraduate students. In its original form this book soon became a classic at a time when fishery science was a rapidly expanding field. The authors have endeavoured to update the book in the light of enormous developments in fishery research during the past two decades. They stress, however, that the book is designed to present principles and applications of fishery management, and assumes that students and practising fishery biologists already have a foundation in the biological, physical and mathematical, and social sciences.

The first two chapters made me feel that the authors' endeavours had been successful. The Introduction refers to systems analysis and describes the new approach to research as a result of the general systems theory. The following chapter on Characteristics of Fisheries is also thought-provoking. The subsequent chapter on Fishing Gear, however, seems quite out of place. It interrupts the flow of the book and seems to have been lifted straight out of the 1953 edition.

Chapter 4 on Population Identification sets our train of thought back on the rails and brings us well up to date 